\title{
Research Paper: Evaluation of Carpal Malalignment Before and After Interpositional Bone Grafting for Treating Scaphoid Nonunion
}

\author{
Hooman Shariatzadeh $^{1}$ (D) , Farhad Soltani', Mohsen Barkam ${ }^{1}$, Ali Dehghan Marvast ${ }^{\text {* }}$ (iD
}

\begin{tabular}{|c|c|}
\hline $\begin{array}{l}\text { Use yuur device to scan } \\
\text { and read the article online }\end{array}$ & Citation Shariatzadeh H, Soltani F, Barkam M, Dehghan Marvast A. Evaluation of Carpal Malalignment Before and After \\
\hline 口ipitis & $\begin{array}{l}\text { Interpositional Bone Grafting for Treating Scaphoid Nonunion. Journal of Research in Orthopedic Science. 2021; 8(3):157- } \\
\text { 162. http://dx.doi.org/10.32598/JROSJ.8.2.785.1 }\end{array}$ \\
\hline 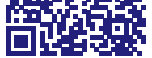 & doi'http://dx.doi.org/10.32598/JROSJ.8.2.785.1 \\
\hline
\end{tabular}

\section{(c) (1) (8)}

Article info:

Received: 29 May 2021

Revised: 10 Jun 2021

Accepted: 02 Jul 2021

Available Online: 01 Aug 2021

Keywords:

Scaphoid, Fracture, Carpal bones, Bone malalignmen

\begin{abstract}
A B S T RA C T
Background: Carpal malalignment following the treatment of scaphoid nonunion increases the risk of Dorsal Intercalated Segment Instability (DISI) and progressive radiocarpal arthrosis.

Objectives: In this study, we aimed to investigate the outcome of interpositional bone grafting without preplanning to correct carpal malalignment in treating scaphoid nonunion.

Methods: Patients and Methods: In a retrospective study, 96 patients who underwent surgery to treat scaphoid nonunion (interpositional bone grafting without correction of carpal malalignment) were included. Indices of carpal malalignment, including the lunocapitate and scapholunate angles, were assessed before and one year after the surgery. A lunocapitate angle of more than $15^{\circ}$ and a scapholunate angle of more than $60^{\circ}$ were considered a sign of DISI.

Results: The study population included 93 men (96.9\%) and three women (3.1\%) with a Mean \pm SD age of $26.1 \pm 3.1$ years. The mean \pm SD time from fracture to nonunion surgery was $8.6 \pm 4.2$ months. The Mean \pm SD lunocapitate angle was $15.2 \pm 13.1^{\circ}$ before and $14.4 \pm 11^{\circ}$ one year after the surgery $(\mathrm{P}=0.48)$. The Mean $\pm \mathrm{SD}$ scapholunate angle was $63.9 \pm 15.2^{\circ}$ before and $64.5 \pm 14.6^{\circ}$ after the surgery $(\mathrm{P}=0.69)$. DISI was present in 67 patients $(69.8 \%)$ before and 66 $(68.8 \%)$ after the surgery. This difference was not statistically significant, too $(\mathrm{P}=0.89)$.

Conclusion: Correction of carpal malalignment should be preoperatively planned to treat scaphoid nonunion to reduce the risk of postoperative DISI and subsequent radiocarpal arthrosis.
\end{abstract}

"Corresponding Author:

Ali Dehghan Marvast, $M D$.

Address: Bone and Joint Reconstruction Research Center, Shafa Orthopedic Hospital, Iran University of Medical Sciences, Tehran, Iran.

Phone: +98 (21) 33542020

E-mail: alidehgha@yahoo.com 


\section{Introduction}

caphoid fractures are the most common fractures of carpal bones, accounting for $60 \%$ to $70 \%$ of carpal bone fractures and $2 \%$ to $7 \%$ of all fractures [1]. In up to $40 \%$ of cases, the scaphoid fracture is missed at initial presentation, leading to an increased risk of nonunion [2]. If the scaphoid nonunion is not adequately treated, it results in severe deformities such as carpal malalignment and its complications, including Dorsal Intercalated Segment Instability (DISI) and progressive radiocarpal arthrosis, which are associated with significant disability $[2,3]$.

Open reduction and internal fixation with interpositional bone grafting is the most common treatment method for scaphoid nonunion that could be done with graft harvested from different bones such as radius and the iliac crest, with or without fixation [4]. Owing to the detrimental impact of carpal malalignment on the outcome of scaphoid nonunion treatment, the emphasis has been placed on correcting the carpal alignment, besides achieving scaphoid union $[5,6]$. Although these therapeutic issues have been discussed and solutions have been provided $[5,6]$, the impact of scaphoid nonunion treatment on the correction of carpal malalignment has only been addressed in a few studies [7-9].

\section{Objectives}

In this study, we aimed to investigate how the carpal malalignment is corrected after treating scaphoid fracture nonunion using open reduction and internal fixation with interpositional bone grafting without preplanning for the correction of carpal alignment.

\section{Methods}

This retrospective research was approved by the Review Board of our institute under the code of IR.IUMS. REC.1400.231. Between 2017 and 2019, the patients' medical records treated for scaphoid nonunion in our Tertiary referral hospital were reviewed. The inclusion criteria were a minimum follow-up of one year and achieving the union of the scaphoid. Patients with a congenital deformity of the wrist or hand, history of distal radius fracture or malalignment, history of fracture at other wrist bones, wrist arthrosis, scaphoid fracture associated with wrist dislocation, and absence of postoperative radiographs were excluded from the study. Finally, 96 patients who met the study criteria were included in the analysis.

\section{Surgical treatment}

Surgery was done with the anterior corticocancellous bone graft augmentation without any preplanning to correct the scaphoid deformity or carpal malalignment. The graft was fixed to the host bone with the pin. After the surgery, the wrist was immobilized in a thumb spica cast for 6-8 weeks. Active wrist excursive was allowed afterward.

\section{Evaluation of carpal malalignment}

Carpal malalignment was determined on the lateral radiography recorded on a picture archiving and communication system. Lunocapitate angle and scapholunate angle were used for this purpose. Lunocapitate angle was defined as the angle between the long axis of the capitate and the mid-axis of the lunate. Scapholunate angle was defined as the angle between the long axis of the scaphoid and the mid-axis of the lunate. A lunocapitate angle smaller than $15^{\circ}$ and a scapholunate angle between $30^{\circ}$ and $60^{\circ}$ were regarded as normal. A lunocapitate angle of greater than $15^{\circ}$ and a scapholunate angle greater than $60^{\circ}$ were regarded as signs of DISI [10].

\section{Statistical analysis}

Statistical analysis was performed using SPSS for Windows, version 16 (SPSS Inc., Chicago, Ill., USA). The descriptive data were presented as Mean $\pm \mathrm{SD}$ or number and percentage. The Kolmogorov-Smirnov test was used to test the normal data distribution. A paired $t$ test or its nonparametric counterpart (Wilcoxon signed-rank test) was used to compare mean values before and after the surgery. The Chi-square test was used to compare the categorical variables. $\mathrm{P}$ values less than 0.05 were considered statistically significant.

\section{Results}

The study population included 93 men $(96.9 \%)$ and 3 women $(3.1 \%)$ with a Mean \pm SD age of $26.1 \pm 3.1$ years. The Mean \pm SD time from fracture to nonunion surgery was $8.6 \pm 4.2$ months. Table 1 presents the patients' characteristics in more detail.

The Mean \pm SD lunocapitate angle was $15.2 \pm 13.1^{\circ}$ before and $14.4 \pm 11^{\circ}$ one year after the surgery. This difference was not statistically significant $(\mathrm{P}=0.48)$. The Mean \pm SD scapholunate angle was $63.9 \pm 15.2^{\circ}$ before and $64.5 \pm 14.6^{\circ}$ after the surgery. This difference was not statistically significant, as well $(\mathrm{P}=0.69)$. 
Table 1. Characteristic of the patients with scaphoid nonunion $(n=96)$

\begin{tabular}{|c|c|c|}
\hline \multicolumn{2}{|c|}{ Variables } & Mean $\pm S D$ or No.(\%) \\
\hline \multicolumn{2}{|c|}{ Age (y) } & $26.1 \pm 3.1$ \\
\hline Gender & $\begin{array}{c}\text { Male } \\
\text { Female }\end{array}$ & $\begin{array}{c}93(96.9) \\
3(3.1)\end{array}$ \\
\hline Hand dominancy & $\begin{array}{l}\text { Right } \\
\text { Left }\end{array}$ & $\begin{array}{l}73(76) \\
23(24)\end{array}$ \\
\hline Smoking & $\begin{array}{l}\text { Yes } \\
\text { No }\end{array}$ & $\begin{array}{l}39(40.7) \\
57(59.3)\end{array}$ \\
\hline Mechanism of injury & $\begin{array}{c}\text { Fall } \\
\text { Sport-related } \\
\text { Motor vehicle accident }\end{array}$ & $\begin{array}{c}19(19.8) \\
52(54.2) \\
25(26)\end{array}$ \\
\hline & & $15.1 \pm 2.9$ \\
\hline Time from fra & surgery (mo) & $8.6 \pm 4.2$ \\
\hline
\end{tabular}

Orthopedic Science

Before the surgery, the lunocapitate angle was more than $15^{\circ}$ in 37 patients $(38.5 \%)$. After the surgery, the lunocapitate angle was more than $15^{\circ}$ in 34 patients $(35.4 \%)(\mathrm{P}=0.75)$. Before the surgery, the scapholunate angle was more than $60^{\circ}$ in 52 patients $(54.2 \%)$. After the surgery, the scapholunate angle was more than $60^{\circ}$ in 59 patients $(61.5 \%)(\mathrm{P}=0.39)$.

Based on the lunocapitate and or scapholunate angle, DISI was present in 67 patients $(69.8 \%)$ before and 66 patients $(68.8 \%)$ after the surgery. This difference was not statistically significant, too $(\mathrm{P}=0.89)$.

\section{Discussion}

Although scaphoid fractures are common, they cause unique therapeutic challenges owing to the particular geometry and vascular pattern of the scaphoid [11, 12]. Delayed diagnosis and inadequate treatment can result in nonunion and subsequent complications such as DISI and degenerative wrist arthritis [12]. In this study, we evaluated how surgical treatment of scaphoid nonunion affects the level of preoperative carpal malalignment. Based on our results, indices of carpal malalignment, including the lunocapitate and scapholunate angle, were not significantly improved after the surgical treatment of scaphoid fracture nonunion. In addition, the number of patients with preoperative DISI almost remained the same after the operation.

Cooney et al. reported the outcome of scaphoid nonunion in 21 patients treated with interpositional anterior wedge grafting and fixation with a Herbert screw. Scaphoid malalignment was measured preoperatively, and the size and shape of the proposed graft were chosen accordingly. Union of scaphoid was achieved in 15 patients $(71 \%)$. The scapholunate angle improved from $65^{\circ}$ to $54^{\circ}$. The capitolunate angle improved from $35^{\circ}$ to $15^{\circ}$. The scaphoid malalignment also improved on biplanar tomographic measurement [13]. We did not investigate the correction of scaphoid malalignment in the present study. The scapholunate angle increased from $63.9^{\circ}$ to $64.5^{\circ}$, while the lunocapitate angle decreased from $15.2^{\circ}$ to $14.4^{\circ}$. These results indicate that concurrent correction of scaphoid malalignment should be considered in scapholunate nonunion treatment.

Trumble et al. reviewed the outcome of scaphoid nonunion in 34 patients treated with interpositional bone grafting and internal fixation with either Herbert screw $(\mathrm{n}=16)$ or $3.5-\mathrm{mm}$ cannulated Osteosynthesis/Association for the Study of Internal Fixation (AO/ASIF) screw $(n=18)$. They did not consider the correction of the scaphoid malalignment during the surgery. The scapholunate angle improved from $51.9^{\circ}$ to $50^{\circ}$ in the Herbert screw group and from $52^{\circ}$ to $47.8^{\circ}$ in the cannulated AO/ASIF screw group. Time of union was significantly lower in the cannulated AO/ASIF screw group [14]. This study revealed that the fixation device could also impact the alignment of the scaphoid after the treatment of scaphoid malunion. In the present study, we used pins for the fixation of interpositional graft.

Nakamura et al. evaluated the impact of scapholunate ligamentous injury and aimed to find whether the ligamentous repair is necessary to treat scaphoid nonunion with DISI. To this aim, they compared the outcome of carpal alignment of scaphoid nonunion with DISI deformity without ligamentous repair to those of scaphoid nonunion without DISI deformity. The scapholunate angle was im- 
proved in 20 out of 22 patients with DISI deformity and 16 out of 19 patients without DISI deformity. They concluded that ligamentous injury hardly causes DISI deformity in scaphoid nonunion, and ligamentous repair is not required to correct DISI deformity in most cases [15]. We did not evaluate ligamentous injury in the present study.

Watanabe aimed to clarify the correlation between a scaphoid deformity and carpal malalignment in 38 patients with scaphoid nonunion and evaluate how a corrective bone graft improves carpal alignment. Surgery was performed by the anterior wedge bone graft method. The scaphoid deformity was assessed with intrascaphoid angle and axial length. Carpal malalignment was assessed with the alterations in the radiolunate angle and scapholunate angle. One year after the surgery, intrascaphoid angle, axial length, radiolunate angle, and scapholunate angle were improved $11^{\circ},-1.3 \mathrm{~mm}, 14^{\circ}$, and $11^{\circ}$, respectively. The level of carpal malalignment was correlated with scaphoid deformity, and corrective bone graft led to the adequate recovery of carpal alignment as preoperatively planned [7]. This study further highlights the value of the correction of scaphoid deformity concurrent with the treatment of scaphoid nonunion. The present study had some limitations. The study's main limitation was the assessment of other indices of carpal malalignment such as radiolunate angle, as well as indices of scaphoid deformity such as intrascaphoid angle and axial length. The retrospective design was the other limitation of the study.

\section{Conclusions}

Correction of scaphoid deformity and carpal alignment should be preoperatively planned in the treatment of scaphoid nonunion. Otherwise, the preoperative DISI would not be resolved, and progressive radiocarpal arthrosis is expected later, causing significant disability for the patients.

\section{Ethical Considerations}

\section{Compliance with ethical guidelines}

This study was approved by the Ethics Committee of the Iran University of Medical Sciences (Code: IR.IUMS.REC.1400.231).

\section{Funding}

This research did not receive any grant from funding agencies in the public, commercial, or non-profit sectors.

\section{Authors' contributions}

Conceptualization: Hooman Shariatzadeh; Methodology: Farhad Soltani; Mohsen Barkam: Data collection; Original draft writing: Ali Dehghan Marvast.

\section{Conflict of interest}

The authors declared no conflict of interest.

\section{References}

[1] Hove LM. Epidemiology of scaphoid fractures in Bergen, Norway. Scand J Plast Reconstr Surg Hand Surg. 1999; 33(4):423-6. [DOI:10.1080/02844319950159145] [PMID]

[2] Nguyen Q, Chaudhry S, Sloan R, Bhoora I, Willard C. The clinical scaphoid fracture: Early computed tomography as a practical approach. Ann R Coll Surg Engl. 2008; 90(6):488-91. [DOI:10.1308/003588408X300948] [PMID] [PMCID]

[3] Mack GR, Bosse MJ, Gelberman RH, Yu E. The natural history of scaphoid non-union. J Bone Joint Surg Am. 1984; 66(4):504-9. [DOI:10.2106/00004623-198466040-00003] [PMID]

[4] Pinder RM, Brkljac M, Rix L, Muir L, Brewster M. Treatment of scaphoid nonunion: A systematic review of the existing evidence. J Hand Surg Am. 2015; 40(9):1797-805.e3. [DOI:10.1016/j.jhsa.2015.05.003] [PMID]

[5] Fisk GR. An overview of injuries of the wrist. Clin Orthop Relat Res. 1980; 149:137-44. [DOI:10.1097/00003086198006000-00016] [PMID]

[6] Fernandez DL. A technique for anterior wedge-shaped grafts for scaphoid nonunions with carpal instability. J Hand Surg Am. 1984; 9(5):733-7. [DOI:10.1016/S0363-5023(84)80025-8] [PMID]

[7] Watanabe K. Analysis of carpal malalignment caused by scaphoid nonunion and evaluation of corrective bone graft on carpal alignment. J Hand Surg Am. 2011; 36(1):10-6. [DOI:10.1016/j.jhsa.2010.10.011] [PMID]

[8] Amadio PC, Berquist TH, Smith DK, Ilstrup DM, Cooney II WP, Linscheid RL. Scaphoid malunion. J Hand Surg Am. 1989; 14(4):679-87. [DOI:10.1016/0363-5023(89)90191-3] [PMID]

[9] Nakamura P, Imaeda T, Miura T. Scaphoid malunion. J Bone Joint Surg Br. 1991; 73(1):134-7. [DOI:10.1302/0301620X.73B1.1991749] [PMID]

[10] Cooney WP. The wrist: diagnosis and operative treatment. Philadelphia: Lippincott Williams \& Wilkins; 2011 https://www.google.com/books/edition/The_Wrist/ qva8f16BewEC?hl=en\&gbpv $=0$

[11] Najd Mazhar F. Scaphocapitate fracture syndrome: A rare case report and literature review. J Res Orthop Sci. 2018; 5(3):e69486. [DOI:10.5812/soj.69486] 
[12] Kawamura K, Chung KC. Treatment of scaphoid fractures and nonunions. J Hand Surg Am. 2008; 33(6):988-97. [DOI:10.1016/j.jhsa.2008.04.026] [PMID] [PMCID]

[13] Cooney WP, Linscheid RL, Dobyns JH, Wood MB. Scaphoid nonunion: Role of anterior interpositional bone grafts. J Hand Surg Am. 1988; 13(5):635-50. [DOI:10.1016/S03635023(88)80116-3] [PMID]

[14] Trumble TE, Clarke T, Kreder HJ. Non-union of the scaphoid. Treatment with cannulated screws compared with treatment with Herbert screws. J Bone Joint Surg Am. 1996; 78(12):1829-37. [DOI:10.2106/00004623-199612000-00005] [PMID]

[15] Nakamura R, Imaeda T, Tsuge S, Watanabe K. Scaphoid nonunion with D.I.S.I. deformity: A survey of clinical cases with special reference to ligamentous injury. J Hand Surg Br. 1991; 16(2):156-61. [DOI:10.1016/0266-7681(91)90167-M] [PMID] 
This Page Intentionally Left Blank 